\title{
PENGARUH SOFT SKILL TERHADAP KINERJA KARYAWAN DI PREMIER BASKO HOTEL PADANG
}

\author{
Khairunnisa $^{1}$, Hijriyantomi ${ }^{2}$ \\ ${ }^{1}$ Program Studi D4 Manajemen Perhotelan Jurusan Pariwisata FPP-UNP \\ ${ }^{2}$ Program Studi D4 Manajemen Perhotelan Jurusan Pariwisata FPP-UNP \\ Corresponding email : khairunnisa.bahrial@yahoo.com
}

\begin{abstract}
Abstrak: Penelitian ini bertujuan untuk menganalisis Pengaruh Soft Skills Karyawan Terhadap Kinerja Karyawan di Premeir Basko Hotel Padang. Jenis penelitian ini adalah jenis penelitian deskriptif kuantitatif dengan metode asosiatif kausal. Populasi dalam penelitian ini adalah seluruh karyawan premier basko hotel padang. Jumlah sampel dalam penelitian ini 70 orang. Metode pengambilan sampel adalah purposive sampling. Teknik pengumpulan data yang digunakan adalah kuisioner tersusun dengan skala likert. Hasil penelitian ini menunjukan bahwa: (1) variabel soft skills telah diperoleh sebanyak $7 \%$ responden termasuk dalam kategori sangat baik, $68 \%$ responden termasuk dalam kategori baik, 19\% responden termsuk dalam kategori cukup, 6\% responden termasuk dalam kategori buruk dan 0\% responden termasuk dalam kategori sangat buruk. (2) variabel kinerja karyawan 13\% responden termasuk dalam kategori sangat baik, 28\% responden termasuk dalam kategori baik, 20\% responden termasuk dalam kategori cukup, $26 \%$ responden termasuk dalam kategori buruk dan $13 \%$ responden termasuk dalam kategori sangat buruk.
\end{abstract}

\section{Kata Kunci : Soft Skills, Kinerja dan Karyawan}

\section{PENDAHULUAN}

Pariwisata merupakan rangkaian aktivitas dan penyediaan layanan baik untuk kebutuhan atraksi wisata, transportasi, akomodasi, maupun laynan lain yang ditujukan untuk memenuhi Kebutuhan perjalanan seseorang atau sekelompok orang.Salah satu sektor pendukung kegiatan wisata yaitu adanya fasilitas dan pelayanan.Sebagaimana diketahui, hotel menyediakan berbagai fasilitas terutama pelayanan kamar dan pelayanan makanan dan minuman yang dapat digunakan oleh siapapun baik wisatawan domestik maupun wisatawan mancanegara. Menurut Sulastiyono (2011:6), "Hotel merupakan suatu jenis akomodasi yang mempergunakan sebagian atau seluruh bangunan untuk menyediakan jasa penginapan, makanan, dan minuman, serta jasa pennjang lainnya bagi umum yang diklola secara komersial. Pihak hotel harus memiliki kriteria untuk setiap karyawan agar dapat memberikan pelayanan maksimal kepada tamu yang dapat diukur melalui kinerja karyawan. Kinerja karyawan adalah kemampuan karyawan dalam mecapai suatu target kerja yang dapat dislesaikan pada tepat waktu atau tidak melampui batas waktu, sehigga kinerja karyawan dapat memberikan kontribusi bagi perusahan tersebut. Namun salah satu faktor yang menentukan kinerja karyawan adalah soft skills. Soft skills sangat penting dlam dunia pekerjaan karena dapat menubuhkan sikap yang merjuk pada sekumpulan karakteristik kepribdian, seperti memiliki sifat tangung jawab, disiplin atau selalu datang tepat waktu dalam setiap pertemuan, dan bekerja sampai detik terakhir

\footnotetext{
${ }^{1}$ Mahasiswa D4 Manajemen Perhotelan FPP - UNP

${ }^{2}$ Dosen Jurusan Pariwisata FPP - UNP
} 
untuk menyelesaikan pekerjaan. Adapun indikator soft skills menurut Sharma (2011: 21), "adalah 1) kemampuan komunikasi, 2) kecerdasan emosional, 3) keterampilan berpikir dan memecahkan masalah, 4) etika dan 5) keterampilan kepemimpinan. Dalam hal ini terlihat soft skills merupakan elemen penting yang harus diperhatikan dalam meningkatkan kinerja karyawan dalam melayani tamu, termasuk di Premier Basko Hotel Padang.

Tabel 1. Kinerja Karyawan Berdasarkan Appraisal Score Premier Basko Hotel Padang pda Bulan Januari - Desember 2018

\begin{tabular}{|c|c|c|c|}
\hline Skor & Jumlah Karyawan & Persentase & Kategori \\
\hline $81-100$ & 9orang & $13 \%$ & Sangat Baik \\
\hline $71-80$ & 14orang & $28 \%$ & Baik \\
\hline $51-70$ & 20 orang & $20 \%$ & Cukup \\
\hline $41-50$ & 18 orang & $26 \%$ & Buruk \\
\hline $20-40$ & 9 orang & $13 \%$ & Sangat Buruk \\
\hline
\end{tabular}

Sumber: Human Resouces Department Premier Basko Hotel Padang(2019)

Berdasarkan Tabel 1 di atas dapat dilihat kinerja karyawan Premier Basko Hotel Padang sebesar 13\% (sangat buruk) dan 26\% (buruk) ini membuktikan bahwa sejumlah 39\% (hampir setengah dari total karyawan) masih dengan hasil kinerja rendah. Menurut HRD Premier Basko Hotel Padang berdasarkan appraisal score buruknya kinerja karyawan dapat dilihat dari penampilan kerja dan sikap kerja.

Berdasarkan penjelasan dari HRD Premier Basko Hotel Padang yang ditemui penulis saat pra penelitian 9 April 2019 terdapat beberapa masalah mengenai kinerja karyawan yang dijelaskan oleh supervisor HK yitu karyawan housekeeping yang menyelesaikan pekerjaan tidak sesuai dengan standar yang ditetapkan, ini terlihat pada saat karyawan housekeeping melakukan make up room. Premier Basko Hotel Padang menetapkan karyawan housekeeping melakukan make up room satu kamar 20 menit, namun masih banyak karyawan yang menyelesaikan lebih dari waktu yang telah ditetapkan.

\section{METODOLOGI}

Penelitian ini tergolong kepada jenis deskriptif kuantitatif dengan metode asosiatif kausal. Populasi penelitian ini adalah seluruh karyawan Premier Basko Hotel Padang.Pengumpulan data melalui angket dengan bantuan skala likert. Teknik analisis penelitian ini menggunakan analisis regresi linear. Seterusnya uji persyaratan analisisnya adalah uji normalitas, homogenitas, linearlitas serta pengujian hipotesis menggunakan regresi linear sderhana untuk melihat besran pengaruh soft skills karyawan terhadap kinerja karyawan.

\section{HASIL DAN PEMBAHASAN}

\section{Hasil Penelitian}

\section{a. Analisis Deskriptif}

Berikut hasil penelitian tentang soft skills dikategorikan pada table berikut ini:

Tabel 2. Distribusi Frekuensi Variabel X (Soft Skills)

\begin{tabular}{|l|l|l|l|}
\hline Kategori & Skor & F & Persentase(\%) \\
\hline $\begin{array}{l}\text { Sangat } \\
\text { baik }\end{array}$ & $\geq 56,1$ & 5 & 7 \\
\hline Baik & $\begin{array}{l}46,7- \\
<56,1\end{array}$ & 16 & 19 \\
\hline Cukup & $37,3-$ & 42 & 65 \\
\hline
\end{tabular}




\begin{tabular}{|l|l|l|l|}
\hline & $<46,7$ & & \\
\hline Buruk & $\begin{array}{l}27,9- \\
<37,3\end{array}$ & 7 & 9 \\
\hline $\begin{array}{l}\text { Sangat } \\
\text { buruk }\end{array}$ & $<27,9$ & 0 & 0 \\
\hline Total & $\mathbf{7 0}$ & $\mathbf{1 0 0}$ \\
\hline
\end{tabular}

Sumber : Data Premeir 2019

Berdasarkan pada tabel di atas dilihat bahwa $7 \%$ responden menyatakan sangat baik, $19 \%$ menyatakan baik, $65 \%$ menyatakan cukup, $9 \%$ menyatakan buruk.

\section{Tabel 3. Data hasil kinerja karyawan Premier Basko Hotel Padang} Variabel Y (Kinerja Karyawan)

\begin{tabular}{|l|l|l|}
\hline Kinerja & Jumlah & Persentase \\
\hline Sangat baik & 9 & $13 \%$ \\
\hline Baik & 14 & $20 \%$ \\
\hline Cukup & 21 & $30 \%$ \\
\hline Buruk & 15 & $21 \%$ \\
\hline Sangat buruk & 11 & $16 \%$ \\
\hline Total & $\mathbf{7 0}$ & $\mathbf{1 0 0 \%}$ \\
\hline
\end{tabular}

Berdasarkan pada tabel di atas dapat dilihat bahwa $13 \%$ responden berpendapat bahwa kinerja karyawan sangat baik, 20\% menyatakan baik, 30\% menyatakan cukup, 21\% menyatakan buruk dan $16 \%$ responden menyatakan sangat buruk.

b. Persyaratan Analisis

\section{1) Uji Normalitas}

Dengn hasil uji normaltas mengenaisoft

skills

karyawan dan kinerja

karyawan dapat dikategorikan pada tabel di bawah ini:

Tabel 4. Hasil Uji Normalitas One-Sample Kolmogorov - Smirnov Test

One-Sample Kolmogorov-Smirnov Test

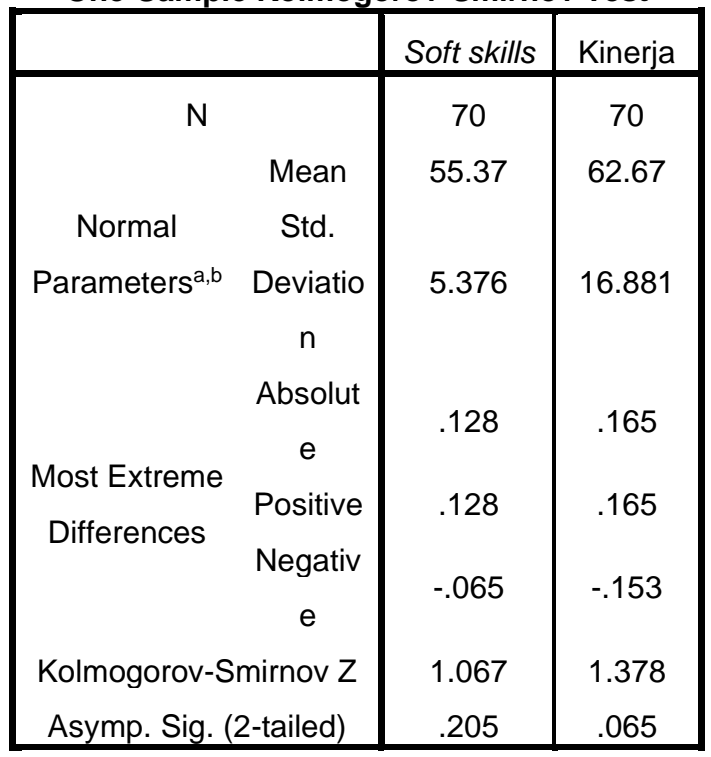

a. Test distribution is Normal. 
Dapat kita lihat nilai Asymp. Sig varible soft skills adlah 205. Nilai signifikansi > 0,05 dan di nyatakan data tersebut normal.

\section{2) Uji Homogenitas}

Dari hasil uji homogenitas mengenai soft skills dan kinerja karyawan dapat dikategorikan

Pada tabel dibawah:

Tabel 5.Hasil Uji Homogenitas Test of Homogeneity of Variances

\begin{tabular}{|c|c|c|c|}
\hline Levene Statistic & $\mathrm{df1}$ & $\mathrm{df2}$ & Sig. \\
\hline 2.310 & 17 & 52 & .711 \\
\hline
\end{tabular}

Uji homogenitas memiliki nilai signifkansi $\quad 0,711 \quad \geq 0,05$. Artinya data bersifat homogeny dan berasal dari populasi yang sama.

\section{3) Uji Linearitas} berikut:

Uji linearitas mengenai soft skills dan kinerja karyawan dapat dikategorikan pada tabel

Tabel 6. Hasil Uji Linearitas

\begin{tabular}{|c|c|c|c|c|c|c|c|}
\hline & & & $\begin{array}{l}\text { Sum of } \\
\text { Squares }\end{array}$ & $d f$ & Mean Square & $F$ & Sig. \\
\hline \multirow{5}{*}{$\begin{array}{l}\text { Kinerja } \\
\text { Karyawan } \\
{ }^{*} \text { Soft skills }\end{array}$} & \multirow{3}{*}{$\begin{array}{l}\text { Between } \\
\text { Groups }\end{array}$} & (Combined) & 6897.510 & 14 & 492.679 & 2.123 & .024 \\
\hline & & Linearity & 44.361 & 1 & 44.361 & .191 & .664 \\
\hline & & $\begin{array}{l}\text { Deviation } \\
\text { from Linearity }\end{array}$ & 6853.148 & 13 & 527.165 & 2.271 & .156 \\
\hline & \multicolumn{2}{|c|}{ Within Groups } & 12765.933 & 55 & 232.108 & & \\
\hline & \multicolumn{2}{|l|}{ Total } & 19663.443 & 69 & & & \\
\hline
\end{tabular}

Nilai uji lineritas dengan nilai signifikansi $0,156>0.05$, yang artinya terdapat hubungan linear secara signifikan antara variabel soft skills dan kinerja karyawan.

c. Pengujian Hipotesis

Dengan hasil uji anova mengenai soft skills karyawan dan kinerja karyawan dapat dilihat pada tabel di bawah ini:

Tabel 7. Regresi Linear Sederhana

ANOVAa
\begin{tabular}{|l|l|l|l|l|l|}
\hline Model & $\begin{array}{l}\text { Sum of Df } \\
\text { Squares }\end{array}$ & $\begin{array}{l}\text { Mean } \\
\text { Square }\end{array}$ & F & Sig. \\
\hline $\begin{array}{l}\text { Regre } \\
\text { ssion }\end{array}$ & 44.361 & 1 & 44.361 & .514 & $.000^{\mathrm{b}}$ \\
$\begin{array}{l}\text { Residu } \\
\text { al }\end{array}$ & 19619.08 & 69 & 288.516 & & \\
Total & 19663.44 & 69 & & & \\
3
\end{tabular}

Sumber: Data Primer, 2019 
Hasil uji anova di atas diperoleh nilai $\mathrm{F}$ hitung 5,14 dengan taraf signifikansi $0.00<0,05$, maka Ha diterima. Artinya soft skills berpengaruh terhadap kinerja karyawan.

\section{Tabel 8. Hasil Uji Koefisien Regresi Variabel X Terhadap Y}

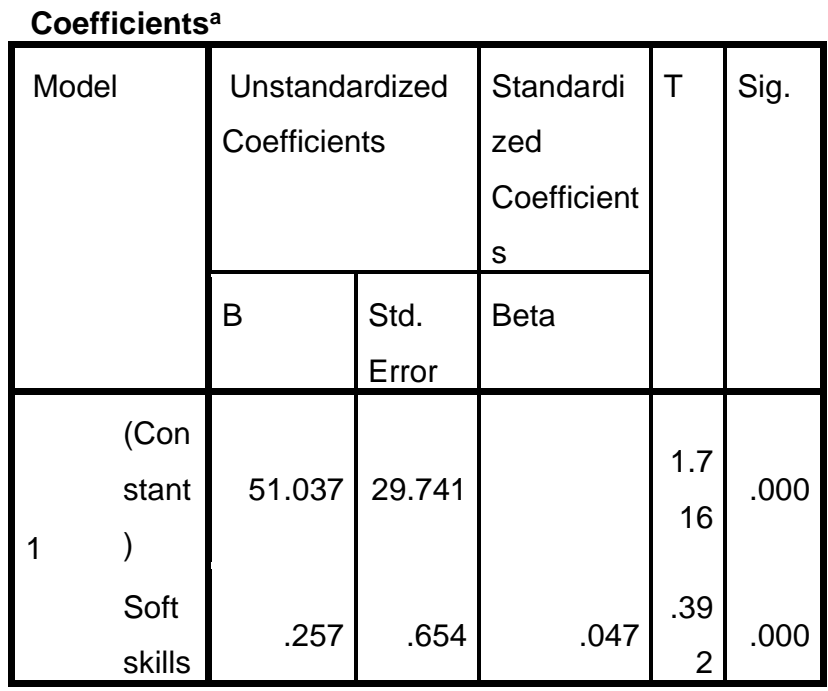

Tabel tersebut mengahasilkan persamaan regresinya yaitu: $\mathbf{Y}=\mathbf{A}+\mathbf{B}=\mathbf{5 1 , 0 3 7 + 0 , 2 5 7} \mathbf{X}$

Berdasarkan tabel diatas diperoleh nilai t sebesar 0,392 dengan taraf Sig 0,000, artinya variabel soft skills (X) mempunyai pengaruh yang signifikan terhadap kinerja karyawan(Y).Selanjutnya diperoleh koefisien regresi 0,257 dengan nilai sig $0,000<0,005$ artinya setiap peningkatan sebesar 1 satuan soft skills akan meningkatkan 0,257 satuan kinerja karyawan.

\section{PEMBAHASAN}

Berdasarkan hasil uji hipotesis yang digunakan untuk mengetahui derajat pengaruh antara soft skills karyawan terhadap kinerja karyawan di Premier Basko Hotel Padang. Analisis dilakukan dengan bantuan SPSS 20.00 diperoleh Nilai $F$ hitung 5,14 dengan taraf signifikansi $0,00<0,05$ yang berarti soft skills berpengaruh terhadap kinerja karyawan. Demikian juga nilai koefisien regresi sebesar 1,100 dengan nilai sig 0,001 < 0,05, diartikan setiap peningkatan sebesar 1 satuan soft skills akan meningkatkan 1,100 satuan kinerja karyawan. Kemudian diperoleh nilai R square 0,015 artinya pengaruh variabel $\mathrm{X}$ terhadap $\mathrm{Y}$ adalah sebesar $0,015(1,5 \%)$.

Sedangkan $98,5 \%$ dipengaaruhi oleh faktor lain. Maka hipotesis yang diterima dalam penelitian ini adalah Ha diterima dan Ho ditolak, dengan demikian soft skills memiliki pengaruh yang signifikan terhadap kinerja karyawan sebesar 1,5\% karena indkator dari soft skills merupakan salah satu factor internal yang dapat mempengaruhi kinerja karyawan sehinga dapat diartikan semakin tinggi soft skills dari kinerja karyawan maka akan meningkatkan kinerja yang dihasilkan karyawan di Premier Basko Hotel Padang. Menurut Wibowo (2016: 3), adalah "Performance sering diartikan sebagai kinerja, hasil kerja atau prestasi kerja. Kinerja mempunyai makna luas, bukan hanya menyatakan sebgaai hasil kerja, tetapi juga bagaimana proses kerja berlangsung. Tentang apa yang dikerjakan dan bagaimana cara mengerjakannya".

Faktor- faktor yang mempengaruhi kinerja karyawan meliputi : pengetahuan, keterampilan, kemampuan kepercayaan diri, sikap dan etika, kepercayaan terhadap sesama dan eksternal akan memberikan pengaruh terhadap kinerja karyawan. Menurut Munandar (2011), "Soft skills adalah kemampuan atau keterampilan seseorang yang menyangkut kehidupan sosialnya yang lebih 
menentukan pada EQ (Emotional Intelligence Quotient) seseorang dibandingkan Intelegence Quotient (IQ) nya. Berdasarkan hasil penelitian tersebut dapat disimpulkan bahwa pengaruh soft skills karyawan terhadap kinerja karyawan di Premier Basko Hotel Padang berpegruh secara signifika. Soft skills berpengaruh cukup besar terhadap kinerja karyawan, dan terdapat factor lain yang dapat mempengaruhi kinerja karyawan seperti pendidikan, keterampilan, disiplin, sikap dan etika kerja, motivasi, gaji dan lainnya.

\section{KESIMPULAN \\ Kesimpulan}

a. Tanggapan responden tentang Softskills karywan di Premier Basko Hotel Padang menunjukan secara kseluruhan pada kategori cukup baik dengan persentase $65 \%$ dikategorikan cukup dan sebanyak $19 \%$ dikategorikan baik. Jadi dapat disimpulkan bahwa soft skills karyawan di Premier Basko Hotel Padang tergolong cukup baik.

b. Hasil penilaian kinerja karyawan di Premier Basko Hotel Padang dikatakan cukup baik dengan persentase sebanyak 30\% dikategorikan cukup dan sebanyak 20\% dikategorikan baik. Jadi dapat disimpulkan bahwa kinerja karyawan di Premier Basko Hotel Padang tergolong cukup baik.

c. Pengaruh Soft skills karyawan terhadap kinerja karyawan di Premier Basko Hotel Padang dengan persentase $1,5 \%$ dan $98,5 \%$ dipengaruhi oleh faktor lain.

\section{DAFTAR PUSTAKA}

[1] HRD Premier Basko Hotel Padang. 2019. Data karyawan Premier Basko Hotel Padang.

[2] Munandar. 2011. Soft Skills Untuk Pendidik. Jakarta: Baduose Media

[3] Sharma. 2011. The Effect of Empowerment and Transformational Leadership on Employee Intentions to Quit: A Study of Restaurant Workers in India. Internasional Journal of Management. Vol.28 No. 1 Part 22 Mei 2019

[4] Sulastiyono. 2011. Manajemen Penyelenggaraan Hotel: Manajemen hotel, Bandung. Alfabeta Wibowo. 2016. Manajemen Kinerja. Jakarta: PT Raja Grafindo Persada. 